appeared. It provides a very satisfactory statement of the legal and psychological implications of this kind of surgery, and gives a much-needed factual background for the psychiatrist and surgeon faced with these trans-sexual problems.

L.R.C.H.

\section{AN ATLAS OF FETAL AND NEONATAL HISTOLOGY}

By M. A. Valdes-Dapena, M.D. Pp. xi +200 , fully illustrated. London: Pitman Medical Publishing Co. Ltd. I 957 . 90s.

As the title implies, this is a histological atlas of the neonatal period which, as claimed in the preface, is a period of increasing importance but which has been neglected. For this reason the book will be very useful even though many of the photographs are not of the highest quality. The work is based on more than 400 cases.

D.M.P.

\section{NEUROPATHOLOGY}

By J. G. Greenfield, M.D., F.R.C.P., LL.D., W. BlackWOOD, M.B., Ch.B., F.R.C.S.E., M.R.C.P.E., W. H. MCMenemeY, M.A., D.M., F.R.C.P., A. MEYER, M.D. and R. M. Norvian, M.D., M.R.C.P., D.P.M. Pp. vi +640 , with 370 illustrations. London: Edward Arnold Ltd. 1958. I05s.

This book is a complete review of the pathology of the central and peripheral nervous systems with the exception of cerebral and spinal tumours. It contains the results of much original work as well as a comprehensive summary of the relevant literature. The standard of the various chapters is uniformly high, and it can be safely stated that there can be no subject of importance connected with the pathology of the nervous system which is not referred to.

It is difficult to pick out any particular section for special mention out of such a wealth of material. Vascular and infectious diseases of the nervous system are fully covered and there is a particularly interesting chapter on malformations of the nervous system and diseases occurring early in life. The demyelinating diseases are discussed in the light of recent knowledge and the dementias and progressive diseases of the basal ganglia are described in detail; all conditions in which the diagnosis may only be established for certain at autopsy.

This book is obviously the product of a great deal of experience in the field of neuropathology and it cannot fail to be of interest and value to any-⿳亠丷厂 one whose work is connected in any way with thisz subject. It is attractively presented, well illustrated and has an excellent bibliography attached to each chapter. It can therefore be unreservedly recom mended and there can be no doubt that it willes become an established book of reference and wilfo prove a fitting memorial to the knowledge and teaching of Dr. J. G. Greenfield.

N.S.G.

\section{AUTONOMIC DYSPRAXIA}

By Brian G. Haynes, M.B., B.S., M.R.C.P. Pp. viii + I22. London: H. K. Lewis \& Co. Ltd. I 958 . I $5 \mathrm{~s}$.

The subtitle: 'An hypothesis for the mechanism of psychosis, neurosis and psychosomatic disease $\stackrel{\omega}{\perp}$ covers rather too broadly the scope of this work, $\omega$ which has little to say about psychosis itself. Theor author defines his title as a physiopathological con-G dition in which the disordered action of autonomic N control has central subcortical origin and stems from emotional overload. Such a condition is said은 to include not only the classical forms of psycho- neurosis and the newer classifications of psychoso- $\infty$ matic medicine, but also a wide variety of " organic diseases such as rheumatic fever, diabetes mellitus, $\frac{\mathbb{D}}{7}$ coronary occlusion, appendicitis, nephritis, leukoK rhoea, thyrotoxicosis and many more.

After an introduction and a chapter on nomenc ture (which is likely to meet with some criticisme; o the book then discusses the functional diseases, t symptoms and physical signs of autonomic dyspraxia, and then diagnosis, prognosis, and treatment. A summary, short bibliography, and index are provided.

The later chapters make it clear that this provoca- $\frac{\varnothing}{\varnothing}$ tive monograph is doing more than renaming the rose, for the author's hypothesis carries practical implications for diagnosis and therapy that cannot 3 be lightly dismissed. Dr. Haynes has been practising what he now preaches for some ${ }_{5} 5$ years; his methods have apparently survived the test of time and remain more successful, in the author's opinion, than those of traditional thinkers. In denigrating the functional-organic dichotomy which forms a major step in so much medical diagnosis, he has gained an important victory for psychosomatic medicine, and gives many original ideas which make this a book which cannot be ignored. We may not $\stackrel{9}{9}$ all agree with his hypothesis, but having studied it, $\rightarrow$ we shall all be better physicians.

\section{L.R.C.H.}

